\title{
Online-Only International Conferences: Strategies for Maintaining Community
}

\author{
Daniel L. Hoffman ${ }^{1}$ (D) Seungoh Paek ${ }^{1}$ (D) $\cdot$ Curtis P. Ho ${ }^{1}$ (D) $\cdot$ Bert Y. Kimura ${ }^{1}$ \\ Published online: 15 June 2021 \\ (C) Association for Educational Communications \& Technology 2021
}

\begin{abstract}
While many academic conferences are transitioning to online events, this article aims to share several strategies used by the organizers of a well-established online-only conference. The Teaching, Colleges, and Community (TCC) Worldwide Online Conference recently celebrated its 25th anniversary. After a brief review of TCC's history, four strategies that organizers have identified as helping conference goers feel oriented, welcomed, connected and engaged are described. These strategies include offering a "pre-conference" orientation, including regional keynote speakers, creating opportunities for informal exchange, and encouraging participation with digital credentials.
\end{abstract}

Keywords Virtual conference $\cdot$ Sense of community $\cdot$ Online conference $\cdot$ Professional meetings

\section{Introduction}

Nearly everyone knows a conference is a "scheduled and formal opportunity for people sharing common interest or vocation to confer with each other" (Anderson \& Anderson, 2010, p. ix). Perhaps what is less known, yet increasingly relevant in an era of pandemic-driven disruption, is the fact that some conferences have been running entirely online for decades. And since online-only conferences are likely to be with us for some time due to SARS-CoV-2, it seems especially critical for the field to share strategies for continuing its important work in virtual contexts. With this context in mind, this article explores several helpful strategies used by organizers of a long-standing, online-only conference.

Specifically, we examine the origins and characteristics of an online conference that celebrated its 25 th anniversary in 2020. The organizers of the Teaching, Colleges, and Community Worldwide Online Conference (TCC) have two and a half decades of experience offering a successful virtual conference on an international scale. To do this over space and time, they have developed a number of strategies for

Seungoh Paek

spaek@hawaii.edu

1 Department of Learning Design and Technology, University of Hawai'i at Mānoa, Honolulu, HI 96822, USA establishing and maintaining a successful online community. Our goal is to share some of these strategies to help others ensure their favorite conferences survive and even thrive online.

\section{Historical Background}

The TCC conference started in 1996. It was initiated by faculty at Kapi'olani Community College in Hawai' $i$ and used email as the primary form of interaction between presenters and participants. The focus of the inaugural conference was teaching in community colleges, which brought together nearly 250 virtual participants from Hawai' $i$ and the rest of the United States (Ho et al., 2011).

From today's vantage point, it is hard to imagine using email as the main means of participating in a conference, especially given concerns about "email anxiety" (Glei, 2016) and "email triage" (Sarrafzadeh et al., 2019). Attempting to run a conference using email only would likely be met with a great deal of hesitancy by modern conference attendees. But in 1996, the TCC organizers leveraged the tools of the time, bringing together individuals connected by a shared passion for teaching and learning. As time passed, TCC evolved in size, scope, and mode of communication. For example, in 2020, TCC involved over 500 participants from 15 different countries. In addition, the event was more synchronous and relied on team communication tools (e.g., Slack) and live video-conferencing (e.g., Zoom). Given its 
history and success, we wanted to share four strategies used by the TCC conference to help others needing to adapt to a virtual conference format.

\section{Strategies for Successful Online Conferences}

\section{Offer a "Pre-Conference" Orientation}

For the 25th anniversary of the TCC conference held in 2020, the organizers hosted a one-day (9:30 AM to 4:00 PM Hawaiian Standard Time), free Commemorative Symposium administered through Adobe Connect and Zoom. The symposium started with an overview of how TCC has evolved over the years followed by several carefully selected talks conference organizers thought would be of interest to a broad range of participants during the pandemic. Topics included a history of technology integration and online distance education, a content analysis of social media data, and online learning technologies for engaging students. In addition, an important part of the symposium was an orientation for conference presenters. This orientation was designed to help presenters and attendees feel more comfortable with presenting, participating, and interacting online. Offering an orientation of this nature created an opportunity for participants feeling anxious about the online conference to 1) ask questions, 2) meet organizers and volunteers, and 3) become familiar with relevant conference technologies. For participants who could not attend the live pre-conference orientation, a recording was made available for asynchronous viewing. Importantly, the orientation was done a month before the main conference program began, which helped ensure participants had plenty of time to practice and prepare for the first day of the conference. Results from the conference's follow-up survey conducted by the organizers indicated the one-day symposium was an informative and reassuring resource for many TCC participants.

\section{Include Regional Keynote Speakers}

Like many conferences, TCC invites distinguished scholars to give keynote addresses each year. However, what the TCC organizers have discovered over time is that it is often beneficial to invite keynote speakers from various geographic regions. In order to be a "worldwide" conference, TCC organizers invite regional keynote speakers, scheduling their presentations according to their respective time zones. This strategy benefits the conference in several ways. First, it is a way to encourage participants from those geographic regions to attend sessions. If those regional keynotes are scheduled during normal working hours for that time zone, attendance increases as participants do not have to navigate unreasonable times (e.g., 5:00 AM or 10:00 PM). Second, many attendees may feel more connected to a conference that is featuring scholars from their regions of the world, which in turn, may help them feel more connected to the broader TCC community. This approach also creates opportunities for participants from different regions to compare and contrast trends occurring across regional boundaries.

Looking back, promoting regional keynote speakers has always been well received by the TCC community. In 2020, for example, TCC extended the idea of having regional keynote presentations by hosting a "A Day in the Life of TCC" event. This particular event was organized to ensure a continuous stream of plenary sessions, scheduled back-to-back, for a complete 24-h cycle. Spanning four regions of the world, the plenary sessions were scheduled during normal working hours across Asia, the Central Pacific, North America, and Europe. Scheduling $24 \mathrm{~h}$ of synchronous sessions was both practical and inspirational. In terms of practicality, organizers wanted to ensure there was at least one live plenary session in every region. In other words, there was always a live session available during the conference regardless of when attendees decided to login. On a more inspirational level, the full $24 \mathrm{~h}$ of plenary sessions were a way to help attendees feel part of something bigger and more global. This was particularly poignant given the 25th anniversary of TCC and the unanticipated challenges of a global pandemic. In sum, the event strived to reduce the distance (psychological and social) between attendees of the online-only conference.

\section{Create Opportunities for Informal Exchange}

Professional conferences usually consist of formal, scheduled presentations. Beyond those, it is well known that an important aspect of conferences is the "creation of opportunities for informal socialization, entertainment, and networking" (Anderson \& Anderson, 2010, p. x). Unfortunately, this sort of casual exchange is less likely in online contexts. To work around this challenge, TCC organizers included a number of casual sessions such as a "Coffee Hour" or a "Happy Hour" in the official program. These informal sessions were intended to simulate a physical space and time for informal conversations and networking. By scheduling these less structured events into the program, organizers encouraged participants to interact in flexible and meaningful ways. Such efforts seemed to work as evidenced by feedback shared via the conference's follow-up survey. Many participants expressed that one of the strengths of the conference was the feeling of belonging to a community, as captured in one anonymous comment: "Sense of community-I always feel welcomed at TCC. It's also great to network with colleagues!"

\section{Encourage Participation with Digital Credentials (Badges)}

For nine years, TCC organizers have integrated digital credentials into the conference experience. Digital credentials such 
as badges are a way of gamifying a non-game context "to direct people's motivations towards intrinsically motivated, gameful experiences and behavior" (Hamari, 2017, p. 469). They have been recognized as an appropriate, easy and efficient way for professional and community groups to reward participants for skills obtained through formal and informal learning (Shields \& Chugh, 2017). At TCC, participants can earn badges by participating in various conference experiences. Some of the badges include the TCC Inspirational Leader badge and the TCC Presenter badge. Another important one is named the TCC Community Builder badge, which recognizes individuals who actively engage with conference themes using social media. It seems digital credentials are yet another useful strategy TCC organizers have used to build and sustain an engaged community over the years.

\section{Conclusion}

The purpose of this paper was to share a few major strategies that have helped make TCC an online success. While the strategies have varied, they all share a common aim of ensuring conference participants feel oriented, welcomed, connected and engaged. Together they emphasize thoughtful planning and the importance of ensuring a virtual conference is designed to be relevant and meaningful to its target audience. We hope sharing this information will help organizers and participants from around the world make smooth transitions to online conferences.

In closing, it is likely that online-only conferences will be with us for some time to come. The good news is the field can turn to veteran organizers of online conferences for insight on what works in different contexts. As the 25 -year history of the TCC conference illustrates - strong communities of educational researchers and practitioners can and will find ways to connect and share knowledge even as the technological and social landscape around them changes.

\section{Declarations}

Conflict of Interest We have no conflicts of interests to disclose.

\section{References}

Anderson, L., \& Anderson, T. (2010). Online conferences: Professional development for a networked era. IAP.

Glei, J. K. (2016). Unsubscribe: How to kill email anxiety, avoid distractions, and get real work done. PublicAffairs.

Hamari, J. (2017). Do badges increase user activity? A field experiment on the effects of gamification. Computers in Human Behavior, 71, 469-478. https://doi.org/10.1016/j.chb.2015.03.036.

Ho, C. P., Kimura, B., \& Boulay, R. (2011). Retrospective analysis of a virtual worldwide conference for eLearning. International Journal for Educational Media and Technology, 5(1), 107-117.

Sarrafzadeh, B., Awadallah, A. H., Lin, C. H., Lee, C. J., Shokouhi, M., \& Dumais, S. T. (2019). Characterizing and predicting email deferral behavior. In Proceedings of the Twelfth ACM International Conference on Web Search and Data Mining (pp. 627-635). https://doi.org/10.1145/3289600.3291028.

Shields, R., \& Chugh, R. (2017). Digital badges-rewards for learning? Education and Information Technologies, 22(4), 1817-1824. https://doi.org/10.1007/s10639-016-9521-x.

Publisher's Note Springer Nature remains neutral with regard to jurisdictional claims in published maps and institutional affiliations. 